\title{
Phosphorylation-Dependent Inhibition by Synapsin I of Organelle Movement in Squid Axoplasm
}

\author{
Teresa L. McGuinness, ${ }^{1, a}$ Scott T. Brady, ${ }^{2}$ John A. Gruner, ${ }^{3}$ Mutsuyuki Sugimori, ${ }^{3}$ Rodolfo Llinas, ${ }^{3}$ and Paul \\ Greengard' \\ 'Laboratory of Molecular and Cellular Neuroscience, The Rockefeller University, New York, New York 10021, ${ }^{2}$ Department \\ of Cell Biology, University of Texas Health Science Center, Dallas, Texas 75235, 3Department of Physiology and \\ Biophysics, New York University Medical Center, New York, New York 10016, and Marine Biological Laboratory, Woods \\ Hole, Massachusetts 02543.
}

Synapsin I, a neuron-specific, synaptic vesicle-associated phosphoprotein, is thought to play an important role in synaptic vesicle function. Recent microinjection studies have shown that synapsin I inhibits neurotransmitter release at the squid giant synapse and that the inhibitory effect is abolished by phosphorylation of the synapsin I molecule (Llinas et al., 1985). We have considered the possibility that synapsin I might modulate release by regulating the ability of synaptic vesicles ta move to, or fuse with, the plasma membrane. Since it is not yet possible to examine these mechanisms in the intact nerve terminal, we have used videoenhanced microscopy to study synaptic vesicle mobility in axoplasm extruded from the squid giant axon. We report here that the dephosphorylated form of synapsin I inhibits organelle movement along microtubules within the interior of extruded axoplasm and that phosphorylation of synapsin I on sites 2 and 3 by calcium/calmodulin-dependent protein kinase II removes this inhibitory effect. Phosphorylation of synapsin I on site 1 by the catalytic subunit of CAMP-dependent protein kinase only partially reduces the inhibitory effect. In contrast to the inhibition of movement along microtubules seen within the interior of the axoplasm, movement along isolated microtubules protruding from the edges of the axoplasm is unaffected by dephospho-synapsin I, despite the fact that the synapsin I concentration is higher there. Thus, synapsin I does not appear to inhibit the fast axonal transport mechanism itself. Rather, these results are consistent with the possibility that dephospho-synapsin I acts by a crosslinking mechanism involving some component(s) of the cytoskeleton, such as F-actin, to create a

\footnotetext{
Received Feb. 13, 1989; revised Apr. 19, 1989; accepted Apr. 26, 1989.

We are grateful to Dr. Raymond Lasek for the use of his microscope. We also thank Philip Leopold and Bea Beverly for valuable technical assistance, Dr. Martin Bahler for performing the synapsin I-vesicle binding studies, Dr. Andrew Czernik for some of the synapsin I used in these experiments, and Dr. Angus C. Nairn for the cAMP-dependent protein kinase catalytic subunit. This work was supported by a Medical Scientist Training Program Fellowship GM-07205 (to T.L.M.), U.S.P.H.S. grants NS-23868 (to S.T.B.), NS-23320 (to S.T.B.), NS-14014 (to R.L.), A.A. 06944 (to P.G.), NS-21550 (to P.G.) and MH-39327 (to P.G.), NSF grant BNS-8511764 (to S.T.B.), and U.S. Air Force Office of Scientific Research grant 85-0368 (to R.L.)

Correspondence should be addressed to Dr. Paul Greengard, Laboratory of Molecular and Cellular Neuroscience, The Rockefeller University, 1230 York Ave., New York, NY 10021.

a Present address: Department of Psychiatry, University of Colorado Health Sciences Center, Denver, CO 80262.

Copyright (C) 1989 Society for Neuroscience $0270-6474 / 89 / 124138-12 \$ 02.00 / 0$
}

dense network that restricts organelle movement. The relevance of the present observations to regulation of neurotransmitter release is discussed.

Synapsin I is a neuron-specific phosphoprotein that is concentrated in presynaptic nerve terminals, where it appears to be associated primarily with the cytoplasmic surface of small synaptic vesicles (Ueda et al., 1973; Ueda and Greengard, 1977; De Camilli et al., 1979, 1983a, b; Huttner et al., 1983; Navone et al., 1984). It is a major substrate for cAMP-dependent protein kinase as well as calcium/calmodulin-dependent protein kinases I and II (CaM kinases I and II) (Huttner and Greengard, 1979; Sieghart et al., 1979; Huttner et al., 1981; Kennedy and Greengard, 1981; Czernik et al., 1987; Nairn and Greengard, 1987). cAMP-dependent protein kinase and CaM kinase I both phosphorylate a single serine residue (site 1) located in the collagenase-resistant head region of the synapsin I molecule, CaM kinase II phosphorylates a pair of serine residues (sites 2 and 3) located in the collagenase-sensitive tail region of the molecule. A variety of studies using intact nerve cell preparations have shown that physiological and pharmacological agents that affect synaptic function also produce alterations in the state of phosphorylation of synapsin I (for reviews, see Nestler and Greengard, 1984; Greengard et al., 1987). In vitro studies have shown that, under certain conditions, phosphorylation of the tail region of synapsin I by CaM kinase II reduces the affinity of synapsin I for the synaptic vesicle membrane (Huttner et al., 1983; Schiebler et al., 1986; Benfenati et al., 1989). Taken together, these studies led to the hypothesis that synapsin I might be involved in the regulation of some aspect of synaptic vesicle function.

The possibility that synapsin I might regulate neurotransmitter release was tested directly by injection of synapsin I into the preterminal digit of the squid giant synapse (Llinas et al., 1985). Injection of the dephosphorylated form of synapsin I decreased neurotransmitter release, whereas injection of synapsin I that had been phosphorylated at sites 2 and 3 in the tail region by CaM kinase II was without effect. Moreover, injection of CaM kinase II itself enhanced release. More recent studies (R. Llinas et al., unpublished observations) have expanded these initial findings and have shown that phosphorylation of site 1 in the head region of synapsin I by cAMP-dependent protein kinase is less effective than tail phospho-synapsin at reducing the ability of synapsin $I$ to inhibit transmitter release at the squid giant synapse. 
We believe that synapsin I is more likely to be involved in modulating than in mediating release, since the fusion-release process per se can occur in less than $200 \mu \mathrm{sec}$ (Llinas et al., 1981), and the turnover rates for the protein kinases are on the order of tens of milliseconds. Furthermore, it is unlikely that synapsin I, which is enriched only in neurons, regulates the exocytotic event itself, a process that is common to all secretory cells. Finally, within nerve terminals, synapsin I appears to be associated only with small (40-60 nm diameter) and not with large (>60 nm diameter) synaptic vesicles (De Camilli et al., 1983a, b; Huttner et al., 1983; Navone et al., 1984; De Camilli and Greengard, 1986). Thus, we think that synapsin I is most likely to be involved in modulating some prefusion property that is unique to small synaptic vesicles.

We have proposed that phosphorylation of synapsin I might regulate the availability of synaptic vesicles for release and that it might do so by regulating the ability of the vesicles to move to or fuse with the plasma membrane (Llinas et al., 1985). Since it is not yet possible to examine these mechanisms in the intact nerve terminal, a number of model systems are currently being used to study the mechanism of action of synapsin I. One of these systems, the extruded axoplasm of the squid giant axon, is the focus of the present report. The present studies were designed to test the possibility that synapsin I regulates the availability of synaptic vesicles for release by affecting the ability of the vesicles to move within the cytoplasm. This required a relatively intact system in which we could directly and clearly visualize vesicle movement. We therefore chose to use videoenhanced contrast-differential interference contrast (VEC-DIC) microscopy techniques to examine the effect of synapsin I on vesicle movement in the extruded squid axoplasm.

VEC-DIC microscopy techniques (Allen et al., 1981; Inoue, 1981) make it possible to detect structures as small as one-tenth the traditional limit of resolution of the light microscope. With these techniques, one can observe subcellular structures the size of individual small synaptic vesicles and microtubules (Allen et al., 1981; Allen and Allen, 1983). The extruded axoplasm preparation from the squid giant axon permits one to perform a variety of manipulations with macromolecules that do not ordinarily cross the plasma membrane and to use VEC-DIC microscopy to observe directly the effects of these manipulations on organelle movement (Brady et al., 1982, 1984, 1985). In addition, the extruded axoplasm preparation provides a useful means for determining if interactions between proteins and subcellular organelles that are suggested on the basis of reconstitution studies with purified components can occur within the axonal milieu. The present results indicate that synapsin I can restrict the ability of vesicles to move within the axoplasm and that this effect is dependent on the state of phosphorylation of the synapsin I molecule. A preliminary report of this work has been published (McGuinness et al., 1987).

\section{Materials and Methods}

Preparation of proteins. Synapsin I was purified in the dephosphorylated form from bovine brain by a modification (Bahler and Greengard, 1987) of the procedure of Schiebler et al. (1986). CaM kinase II was purified from rat forebrain as described by McGuinness et al. (1985), with the addition of hydroxylapatite chromatography inserted between the DEAEcellulose chromatography and ammonium sulfate precipitation steps. Purified CaM kinase II $(0.4-0.5 \mathrm{mg} / \mathrm{ml})$ was dialyzed extensively against buffer A (10 mM HEPES, pH 7.2, $150 \mathrm{~mm}$ potassium aspartate, $5 \mathrm{~mm}$ $\mathrm{MgSO}_{4}$ ) and stored at $-70^{\circ} \mathrm{C}$. The catalytic subunit of cAMP-dependent protein kinase was purified as described by Kaczmarek et al. (1980).
Calmodulin was purified as described by Grand et al. (1979). Protein determinations were performed by the method of Peterson (1977), using BSA as standard.

Synapsin $I(0.35 \mathrm{mg} / \mathrm{ml})$ was phosphorylated by incubation for 30 min at $30^{\circ} \mathrm{C}$ in $50 \mathrm{~mm}$ Tris- $\mathrm{HCl}, \mathrm{pH} 7.5,150 \mathrm{~mm} \mathrm{NaCl}, 0.4 \mathrm{~mm}$ EGTA, $1 \mathrm{~mm}$ dithioerythritol, $10 \mathrm{mM} \mathrm{MgCl}, 100 \mu \mathrm{M}$ ATP, with trace amounts of $\gamma$ - ${ }^{32} \mathrm{P}$-ATP, with either CaM kinase II $(3.4 \mu \mathrm{g} / \mathrm{ml}), 0.7 \mathrm{~mm} \mathrm{CaCl}, 30$ $\mu \mathrm{g} / \mathrm{ml}$ calmodulin or the catalytic subunit of cAMP-dependent protein kinase (60 nM), 0.1\% Nonidet-P40. “Mock"-phospho-synapsin I was treated as above except that both kinases, $\mathrm{CaCl}_{2}$, calmodulin, and Nonidet-P40 were added, and ATP was omitted from the reaction mixture. Phosphorylation reactions were terminated by the addition of EDTA to a final concentration of $20 \mathrm{~mm}$. One- and 2-dimensional peptide mapping (Kennedy and Greengard, 1981; Huttner et al., 1981; Kennedy et al., 1983) revealed that synapsin I was phosphorylated to a stoichiometry of $1.0 \mathrm{~mol} / \mathrm{mol}$ on site 2 and on site 3 by CaM kinase II and to a stoichiometry of $0.95 \mathrm{~mol} / \mathrm{mol}$ on site 1 by the catalytic subunit of cAMP-dependent protein kinase.

Some of the phosphorylated and dephosphorylated synapsin I preparations were fluorescently labeled with Texas red (Molecular Probes, Inc., Eugene, OR) according to the method of Titus et al. (1982) as described by Llinas et al. (unpublished obervations). The various forms of synapsin I were re-purified from kinases and/or unbound Texas red by $\mathrm{CM}$-cellulose chromatography at $\mathrm{pH} 8.0$ as described by Llinas et al. (unpublished observations), using buffer $A$ for elution. The re-purified synapsin I was concentrated, dialyzed against buffer $A$, centrifuged in a Beckman TL 100 centrifuge at $450,000 \mathrm{~g}$ for $15 \mathrm{~min}$ to remove large aggregates, stored at $0-4^{\circ} \mathrm{C}$, and used within $7 \mathrm{~d}$ of preparation or stored at $-70^{\circ} \mathrm{C}$ and thawed immediately before use. Labeled and unlabeled synapsin I preparations were assayed for the ability to be phosphorylated by CaM kinase II using the procedure of McGuinness et al. (1985), to bind to purified synaptic vesicles using the procedure of Schiebler et al. (1986), to inhibit neurotransmitter release using the procedure of Llinas et al. (1985), and to inhibit organelle movement using the methods described in the present report.

Manipulation of axoplasm. Squid (Loligo pealei) having a mantle length of $10-20 \mathrm{~cm}$ were obtained daily from the Department of Marine Resources, Marine Biological Laboratory (Woods Hole, MA). Postganglionic squid giant axons were dissected, and each axoplasm was extruded onto a glass coverslip. The axoplasm was then covered with a second glass coverslip for viewing by VEC-DIC microscopy as previously described (Brady et al., 1985; Schroer et al., 1985). After recording baseline organelle movement, axoplasm was incubated with $20-40 \mu \mathrm{l}$ of either buffer B (buffer A plus 1 mM ATP) alone or buffer B containing 1.3-10 $\mu \mathrm{M}$ synapsin I.

For the kinase injection experiments, axoplasm was extruded onto a glass coverslip, and CaM kinase II $(0.4 \mathrm{mg} / \mathrm{ml}$ in buffer A) was injected from a microelectrode by means of short pressure pulses ( $20-65 \mathrm{psi}$, $\sim 100 \mathrm{msec}$ in duration) into a small region of the axoplasm. The axoplasm was then covered with a second coverslip for viewing by VECDIC microscopy. After recording baseline organelle movement, $20-40$ $\mu$ l of buffer B containing 1.3-10 $\mu \mathrm{M}$ dephosphosynapsin I, $40 \mu \mathrm{M} \mathrm{CaCl}_{2}$, and $0.15 \mathrm{mg} / \mathrm{ml} \mathrm{calmodulin}$ was applied to the chamber.

The rapid directed movement of membranous organelles within extruded axoplasm occurs in both the anterograde (from the cell body to the terminals) and the retrograde (from the terminals to the cell body) directions and, in neurons, is referred to as fast axonal transport (for review; see Grafstein and Forman, 1980). Fast transport has been shown, using VEC-DIC techniques, to occur along individual microtubules (Hayden et al., 1983; Allen et al., 1985; Schnapp et al., 1985). Recent evidence suggests that the translocating enzyme that may be responsible for anterograde transport is different from that responsible for retrograde transport (Vale et al., 1985 a, c; Paschal and Vallee, 1987; Paschal et al., 1987). In all the figures, the axoplasm was oriented horizontally such that the proximal or cell body end of the axoplasm is to the left and the distal or terminal end is to the right. Thus, movement from left to right is in the anterograde direction, and movement from right to left is in the retrograde direction.

Video-enhanced microscopy. Organelle movement was visualized using DIC optics on a Zeiss Axiomat microscope (with $100 \times$ objective, zoom set at $2.5 \times$ ) using a Chalnicon videocamera (Hamamatsu Systems, Inc., Waltham, MA). A silicon-intensified target camera (Hamamatsu) and rhodamine filter set (Carl Zeiss, Inc., Thornwood, NY) were used for fluorescence imaging. Video images were processed with a Hamamatsu C-1440 or C-1966 Image Processor (Photonics Micros- 
copy, Inc., Oak Brook, IL) to enhance contrast and to eliminate background optical noise. Video signals were recorded in real-time ( 30 frames/ $\mathrm{sec}$ ) on a Sony VO-5850 videotape recorder.

Depending on the particular biological preparation used, one can examine various parameters of fast axonal transport, including the number and types of organelles moving, their velocity, and the direction of movement. However, the intact extruded axoplasm preparation is not amenable to quantitation of the number of organelles moving per unit time. The number of moving particles in a single plane of focus within a hcalthy axoplasm is so numerous and the smallest organelles, which are the ones of interest in the present studies, have such low contrast that they are detected primarily as a continuous streaming across the screen. Because such organelles are well below the limit of resolution of the light microscope, it is physically impossible to distinguish these small moving particles as individual elements. Any estimate of the number of particles moving across even a short line drawn on the screen could be in error by orders of magnitude. In previous studies using intact axons (e.g., Allen et al., 1982; Adams and Bray, 1983; Forman et al., 1983; Koenig, 1986) or neurites in culture (e.g., Hollenbeck and Bray, 1987), only a fraction of the total number of moving particles was detected. In fact, the inability to detect the small synaptic vesicle-sized particles in these preparations reduced the total number of visible moving particles so that the small number of larger moving organelles could be counted. In previous studies using dissociated axoplasm (e.g., Allen et al., 1985; Schnapp et al., 1985; Vale et al., 1985b; Weiss, 1986), individual translocation events could be easily examined. For some of the intact and dissociated preparations, estimales were presented of the number of moving particles. However, no attempt was made in any of these studies to evaluate the sampling procedure to determine the population of organelles being counted or how these relate to the complete set of organelles in transport. Fortunately, in the present study, the effect of the dephosphorylated form of synapsin I on organelle movement was so dramatic that precise quantitation of the number of organelles affected was not critical.

Velocity measurements were performed with a Hamamatsu C-2117 video manipulator, which generates white pixels that move across the monitor. The direction and rate of these pixels were adjusted by eye to corrcspond alternatcly to the average velocity of particles moving in the anterograde or retrograde directions. Velocities are expressed as mean \pm SEM.

The "trace" images were obtained using the Hamamatsu C-1966 Image Processor to extract a trace of moving objects by sequentially subtracting frames at specified intervals and accumulating the successive subtracted images. We had hoped to calculate the total intensities of the trace images and to use the intensity values as a quantitative measure of total movement. This could be done by using a root-mean-square average of the subtracted images as described by Forscher et al. (1987). However, several limitations inherent in the trace technique precluded its routine use in the present studies. Situations that limit the usefulness of this technique include too many moving particles for their trajectories to be resolved from one another, variation in intensity of illumination duc to fluctuations of the light source or differences in the depth of focus, and particles moving in and out of the plane of focus. The first limitation is the reason why only the trajectories of the high-contrast, mediumsized and large organelles could be clearly seen in Figure $2 A$. Unfortunately, we were most interested in the movements of the low-contrast, small (synaptic vesicle-sized) organelles, which were lost in the back- ground video noise. In addition, fluctuations in the illuminator and slight changes in the depth of focus during the course of a $1 \mathrm{hr}$ experiment often made it impossible to compare directly the trace image or total intensity of the image before and after the experimental manipulation. As a result, this procedure provided a qualitative means of comparison but was not well suited for quantitative comparison of movement in axoplasm.

\section{Results}

Effect of dephospho-synapsin I on organelle movement within the interior of the axoplasm

In agreement with previous reports (Brady et al., 1982, 1984, 1985), in preparations that were not exposed to synapsin I, transport of organelles along microtubules was maintained for several hours after extrusion of the axoplasm. The situation in the presence of the dephosphorylated form of synapsin I is illustrated in Figure 1 and Table 1, where it can be seen that incubation of isolated axoplasm with dephospho-synapsin I resulted in an almost complete inhibition of directed organelle movement. Immediately before addition of dephospho-synapsin I, organelles of all sizes were seen moving in both anterograde and retrograde directions (Fig. $1, A, B$ ). In contrast, by $1 \mathrm{hr}$ after addition of dephospho-synapsin I to the axoplasm, virtually all directed organelle movement within the interior of the axoplasm came to a complete halt (Fig. $1, C, D$ ). The smallest organelles appeared to be the most quickly and completely affected, but by $30 \mathrm{~min}$ to $1 \mathrm{hr}$ after addition of dephospho-synapsin I, organelles of all sizes were clearly affected. In the absence of dephospho-synapsin $I$, the average velocity of particles moving in the anterograde and retrograde directions was $1.72 \pm 0.098 \mu \mathrm{m} /$ $\sec (n=33)$ and $1.29 \pm 0.042 \mu \mathrm{m} / \mathrm{sec}(n=33)$, respectively (S. T. Brady and G. S. Bloom, unpublished observations; and the present report). After equilibration of the axoplasm with dephospho-synapsin I, the average velocity in both directions for most particles was essentially zero.

No detectable change in the structural organization of the axoplasm was noted on the addition of dephospho-synapsin I. For example, in contrast to results obtained with purified microtubules (Baines and Bennett, 1986), no dephospho-synapsin I-induced bundling of microtubules was detected in the intact axoplasm. Furthermore, there was no loss of order or increase in Brownian motion, which can be seen in disrupted axoplasm or axoplasm depletcd of ATP (Brady et al., 1985). Instead, the axoplasm appeared to virtually freeze in the presence of dephospho-synapsin I, with many organelles undergoing repeated short "tugging" movements. This tugging behavior could represent constrained Brownian movement of particles trapped

Figure 1. Effect of dephospho-synapsin I on organelle movement within the interior of the axoplasm. Stills from video records show organelle movement within the interior of extruded axoplasm immediately before $(A, B)$ and $1 \mathrm{hr}$ after $(C, D)$ addition of $10 \mu \mathrm{M}$ dephospho-synapsin $\mathrm{I}$. Arrows and arrowhead in $A$ point to a few of the numerous organelles that had moved during the 5.5 sec interval between frames $A$ and $B$. The corresponding symbols in $B$ point to the positions originally occupied by the respective organelles. Solid, curved arrow in $A$ points to a mitochondrion that moved to the left, as seen in $B$. Open, curved arrow in $A$ points to a large organelle that moved upward and to the right, as seen in $B$. Solid, thin arrow and solid arrowhead in $A$ point to 2 smaller organelles that moved out of the field in $B$. Open, straight arrow in $A$ points to 2 organelles that moved in opposite directions in $B$. These 2 organelles are marked with an ${ }^{*}$ in both $A$ and $B$; the top organelle moved in the retrograde direction, whereas the bottom organelle moved in the anterograde direction. In contrast to the movement observed between frames $A$ and $B$, almost no organelles moved during the $5.5 \mathrm{sec}$ interval between frames $C$ and $D$. Arrows and arrowheads in $C$ and $D$ indicate just a few of the varioussized organelles that remained stationary in the presence of dephospho-synapsin I. Stills were made by playing the original videotape into the C-19.66 Image Processor, performing a rolling average of 4 frames, and recording the averaged image onto an optical disc using a Panasonic TQ2028F Optical Memory Disc Recorder. Single frames from the optical disc were photographed from a high-resolution monochrome monitor with a $35 \mathrm{~mm}$ camera onto Kodak Tech-pan film. Scale bar, $2 \mu \mathrm{m}$. 

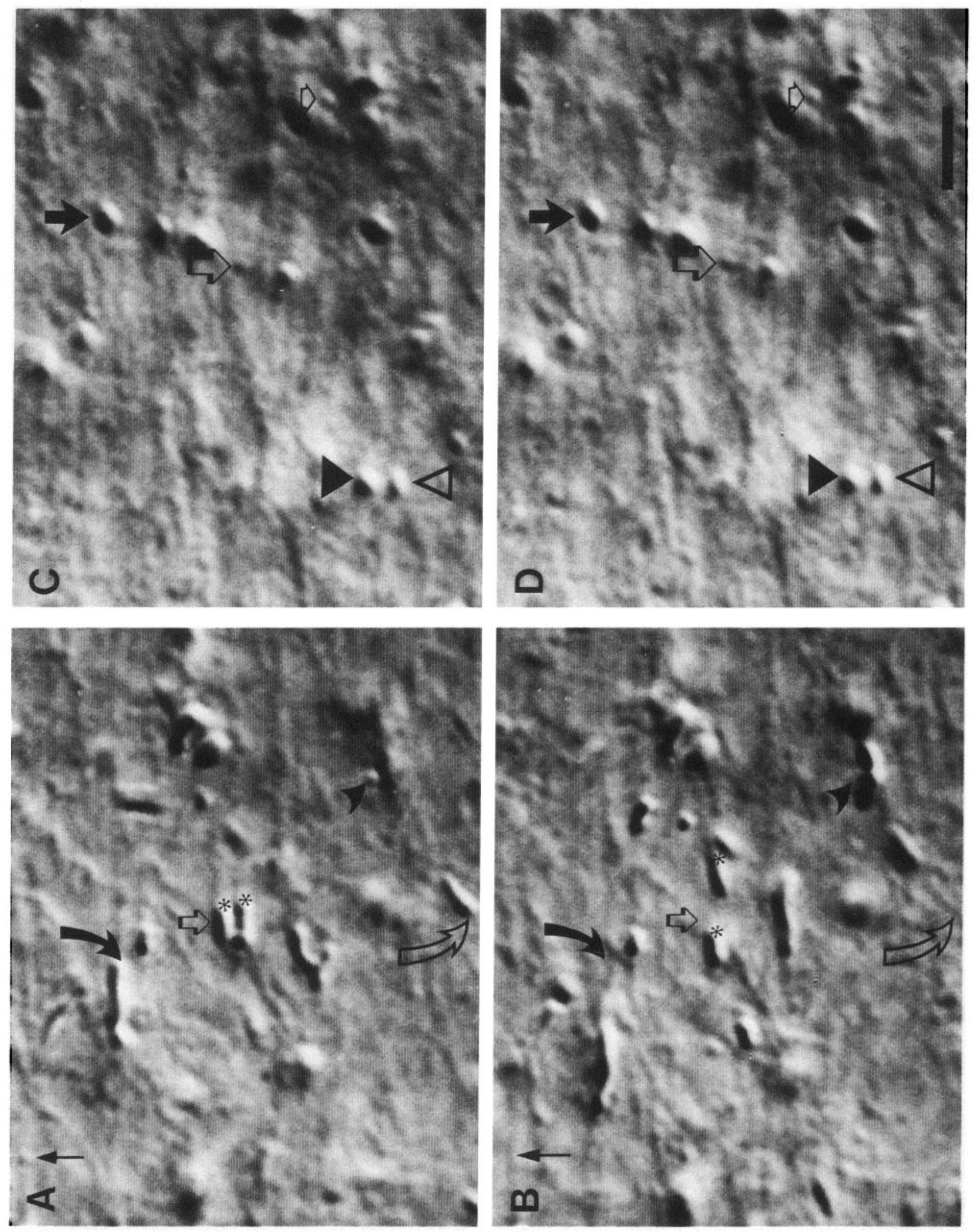

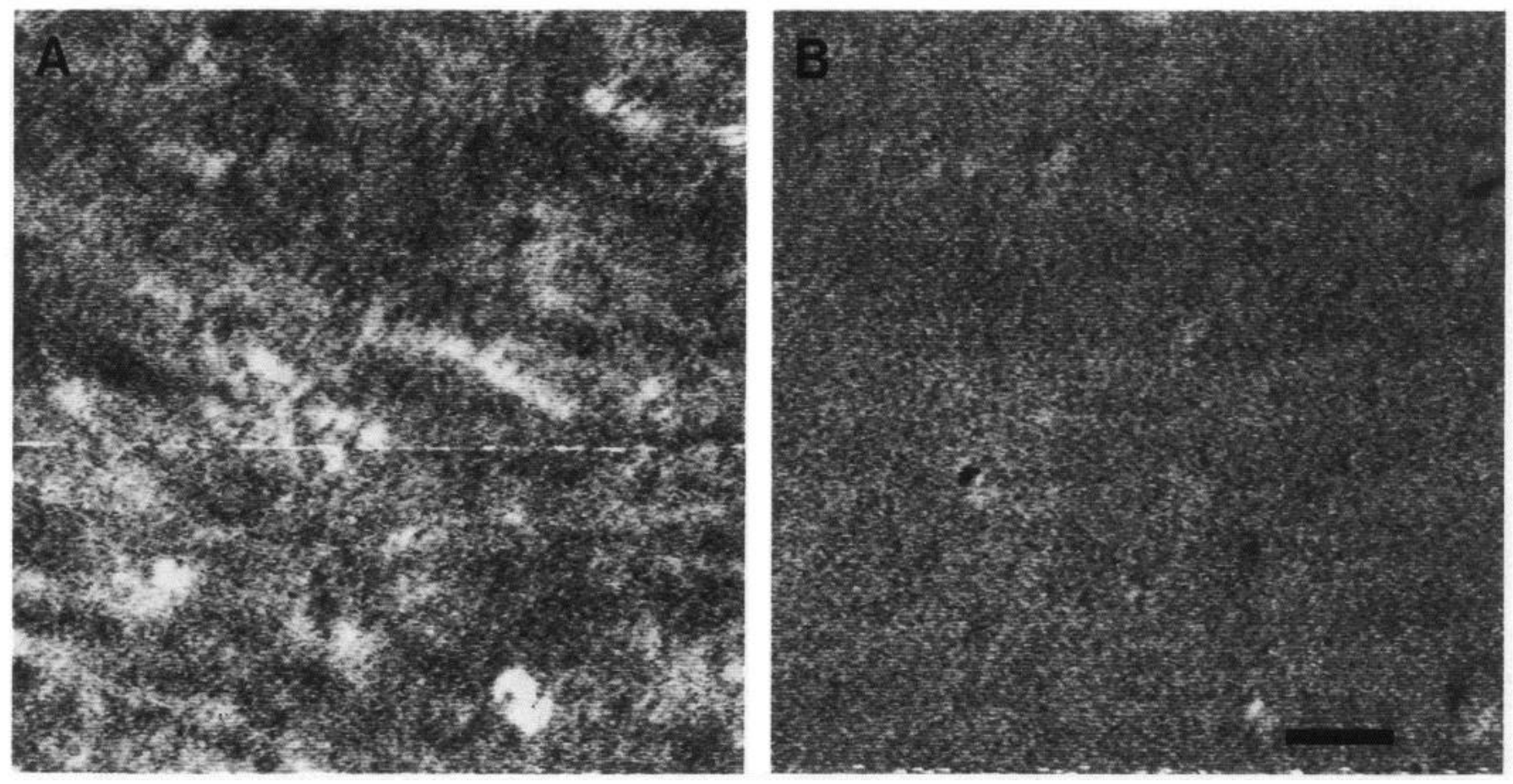

Figure 2. Trace images illustrating the effect of dephospho-synapsin I on organelle movement within the interior of the axoplasm. Traces were obtained by subtracting every third frame $(0.1 \mathrm{sec}$ intervals) and accumulating the subtracted images of 60 frames, as described in Materials and Methods. $A$, Linear paths produced by moving organelles within the axoplasm immediately before addition of dephospho-synapsin I. $B$, No such paths can be detected in the same axoplasm $1 \mathrm{hr}$ after addition of $10 \mu \mathrm{M}$ dephospho-synapsin I. Stills were made by copying the original videotape onto an optical disc and photographing single frames as described in the legend to Figure 1. Scale bar, $2 \mu \mathrm{m}$.

within the matrix of the axoplasm (Brady et al., 1985) or could represent attempted movement of organelles that are actually tethered to some component of the axoplasmic matrix. Replenishing the ATP did not reverse the inhibitory effect of dephospho-synapsin I on axonal transport.

Regions in which directed movement had ceased within the axoplasm were first detected within 5 min after dephosphosynapsin I addition and were detected throughout the axoplasm by $30 \mathrm{~min}$. To monitor the diffusion of synapsin I into the axoplasm, the protein used for most of these experiments was fluorescently labeled with the rhodamine derivative Texas red. Labeled synapsin I was comparable to unlabeled synapsin I in

Table 1. Effect of dephospho-synapsin I and phospho-synapsin I on organelle movement within extruded axoplasm

\begin{tabular}{lll} 
Condition & $\begin{array}{l}\text { Synapsin } \\
\text { concen- } \\
\text { tration } \\
(\mathrm{mg} / \mathrm{ml})\end{array}$ & $\begin{array}{l}\text { Organelle } \\
\text { movements } \\
\text { (after } 30 \\
\mathrm{~min})\end{array}$ \\
\hline Control & 0 & ++++ \\
Dephospho-synapsin I & 0.1 & + \\
& 1.0 & 0 \\
Mock phospho-synapsin I & 0.1 & + \\
& 1.0 & 0 \\
Tail phospho-synapsin I (calmodulin & 0.1 & ++++ \\
kinase II treated) & 1.0 & +++ \\
Head phospho-synapsin I (cAMP- & 0.1 & +++ \\
dependent protein kinase treated) & & \\
\hline
\end{tabular}

terms of its ability to be phosphorylated by CaM kinase II, to bind to purified synaptic vesicles, to inhibit organelle movement (present report), and to inhibit neurotransmitter release (Llinas et al., unpublished observations). Fluorescent dephospho-synapsin I was found to penetrate the axoplasm with a time course similar to that found for the appearance of the inhibitory effect. This time course is consistent with that expected for diffusion of molecules the size of synapsin I in squid axoplasm (Brady et al., 1984, 1985; Morris and Lasek, 1984).

Dynamic movement observed in real-time using video-enhanced microscopy cannot be adequately represented in still photographs. The isolated axoplasm preparation contains so many moving organelles that frames selected at 2 different times may look very similar because almost all organelles have moved in the interframe interval and other organelles have taken their place. Often, only the positions of medium-sized and large organelles can unequivocally be identified in successive still photographs. Furthermore, the ability to even detect the small synaptic vesicle-sized particles within the complex interior of the axoplasm is almost completely lost in the still picture. The changes in contrast generated by the movement of these particles contribute significantly to one's ability to study them.

Figure 2 represents an attempt to circumvent these limitations. The trace images in Figure 2 were obtained by sequentially subtracting DIC images captured at $0.1 \mathrm{sec}$ intervals and accumulating 60 of the subtracted images. Trajectories of moving particles were visualized by changes in pixel brightness caused by movement during the interframe interval. The trajectories created by organelles moving within the axoplasm were clearly seen before addition of dephospho-synapsin I (Fig. $2 A$ ). In con- 
trast, no trajectories were evident $1 \mathrm{hr}$ after dephospho-synapsin I was applied to the axoplasm (Fig. 2B). This trace imaging technique provided a qualitative measure of the extent to which dephospho-synapsin I reduced movement of organelles.

\section{Effect of dephospho-synapsin I on organelle movement at the periphery of the axoplasm}

The most peripheral region of the extruded axoplasm preparation, i.e., the region nearest the buffer-axoplasm interface, has a less dense and less ordered organization than does the interior of the axoplasm proper (cf. Fig. 3, $A, B$ to $C, D$, and see Brady et al., 1982; Miller and Lasek, 1985). In the periphery, organelle movement is not inhibited by dephospho-synapsin I. In contrast to the immobilization of particles produced by dephospho-synapsin I within the interior of the axoplasm (Fig. 3, $A, B$ ), organelle movement along microtubules near the boundary between the buffer and axoplasm (Fig. 3, $C, D$ ) was unaffected by dephospho-synapsin I. Typically, regions of the axoplasm more than 5-6 $\mu \mathrm{m}$ away from the boundary between buffer and axoplasm were clearly reduced in the amount of organelle movement within 10 min of dephospho-synapsin I addition. As the incubation continued, almost all organelle movement ceased within the interior of the axoplasm (Fig. 3, $A, B$ ). Throughout the course of the experiment, however, organelles of all sizes in the most superficial regions of axoplasm continued to move along easily resolved microtubules (Fig. 3, $C, D$ ). Similarly, organelle movement along isolated microtubules protruding from the edge of the axoplasm continued in the presence of dephospho-synapsin I (Fig. 4). Thus, axonal transport along individual microtubules in the periphery of the axoplasm and in the surrounding buffer continued unabated, despite the fact that the dephospho-synapsin I concentration was higher in these peripheral regions than in the interior of the axoplasm, as determined by fluorescent monitoring of Texas red-labeled synap$\sin I$.

\section{Effect of phospho-synapsin I on organelle movement}

Phosphorylation of sites 2 and 3 in the tail region of the synapsin I molecule by CaM kinase II abolishes the ability of synapsin I to inhibit transmitter release at the squid giant synapse (Llinas et al., 1985; unpublished observations). Therefore, we examined whether phosphorylation of synapsin I by CaM kinase II would also reduce the ability of synapsin I to inhibit organelle movement in the squid giant axoplasm. As shown in the previous section, organelle movement was almost completely inhibited when axoplasm was incubated with 1.3-10 $\mu \mathrm{M}$ dephospho-synapsin I. In contrast, incubation of axoplasm with $1.3 \mu \mathrm{M}$ tail phospho-synapsin I (synapsin I that had been phosphorylated on sites 2 and 3 in the tail region of the molecule by CaM kinase II) had no effect on organelle movement (see Table 1), and incubation with $10 \mu \mathrm{M}$ tail phosphosynapsin I had only a slight inhibitory effect (Fig. 5). This minor effect at the higher concentration might have resulted from sites 2 and 3 being incompletely phosphorylated or partially dephosphorylated by endogenous squid protein phosphatase(s). The fact that $10 \mu \mathrm{M}$ tail phospho-synapsin I had little effect on transport indicates that this concentration of dephospho-synapsin I, which abolished organelle movement, did not per se cause a nonspecific perturbation of axonal transport.

Phosphorylation of site 1 in the head region of the synapsin I molecule by cAMP-dependent protein kinasc only partially reduced the ability of synapsin I to inhibit organelles from being transported along microtubules. Phosphorylation by cAMP-dependent protein kinase was not as effective as phosphorylation by CaM kinase II in preventing the inhibitory effect of synapsin I, but far more movement was seen in axoplasm treated with head phospho-synapsin I than if treated with dephospho-synapsin I (sce Table 1).

The relative lack of effect of the phospho-synapsin I preparations was not due to nonspecific inactivation of the molecule by the phosphorylation conditions, since mock phosphosynapsin I (synapsin I that had been treated identically to phospho-synapsin I except that ATP was omitted from the phosphorylation reaction mixture) was indistinguishable from dephospho-synapsin I in its inhibitory effect. The relative lack of effect of the phospho-synapsin I preparations was also not due to poor penetration into the axoplasm, since fluorescence monitoring of Texas red-labeled synapsin I showed similar diffusion for the dephospho- and phospho-forms. The differences in transport blocking ability between dephospho- and phospho-synapsin I were also observed when the proteins were pressureinjected from a microelectrode directly into a small region of the axoplasm. In these experiments, dephospho-synapsin I inhibited movement in the region surrounding the injection site, whereas axonal transport proceeded normally at distances farther away. In contrast, phospho-synapsin I had no effect.

The microinjection technique was also used to test whether phosphorylation of synapsin I within the axoplasm itself by CaM kinase II would prevent the inhibitory action of synapsin I on organelle movement. CaM kinase II was pressure-injected into a small area at the distal end of the axoplasm. Organelle movement and the integrity of the axoplasm in the vicinity of the injection site were not noticeably different from that seen in other regions. The axoplasm was then incubated with buffer containing 1.3-10 $\mu \mathrm{M}$ dephospho-synapsin I in the presence of $40 \mu \mathrm{M}$ calcium and $0.15 \mathrm{mg} / \mathrm{ml}$ calmodulin to promote phosphorylation. Incubation with these concentrations of calcium and calmodulin without dephospho-synapsin I had no detectable effect on organelle movement (Brady et al., 1984, 1985; and this study). Dephospho-synapsin I inhibited movement throughout the axoplasm except in the immediate vicinity of the kinase injection site. Near the injection site, normal organelle movement was observed. Decreases in organelle movement were seen with increasing distance from the site of injection. The distribution and intensity of the fluorescent synapsin I was the same at the injection site as in other regions. Thus, inhibition by dephospho-synapsin I can be prevented by CaM kinase II within the axoplasm itself.

\section{Discussion}

The present studies utilized the isolated axoplasm from the squid giant axon as one model for studying the mechanism by which synapsin I might regulate neurotransmitter release. These studies were undertaken to test the following hypothesis. If synapsin I regulates availability of synaptic vesicles for release by restricting the ability of vesicles to move within the cytoplasm of the presynaptic terminal, then adding concentrations of synapsin I that would be expected to exist within the terminal to the isolated axoplasm might inhibit vesicle movement in the axoplasm. This is, in fact, what was found (see Table 1). The dephosphorylated form of synapsin I virtually abolished all vesicle movement within the interior of the isolated axoplasm. Phosphorylation of synapsin I by CaM kinase II removed the inhibitory effect and phosphorylation by cAMP-dependent pro- 

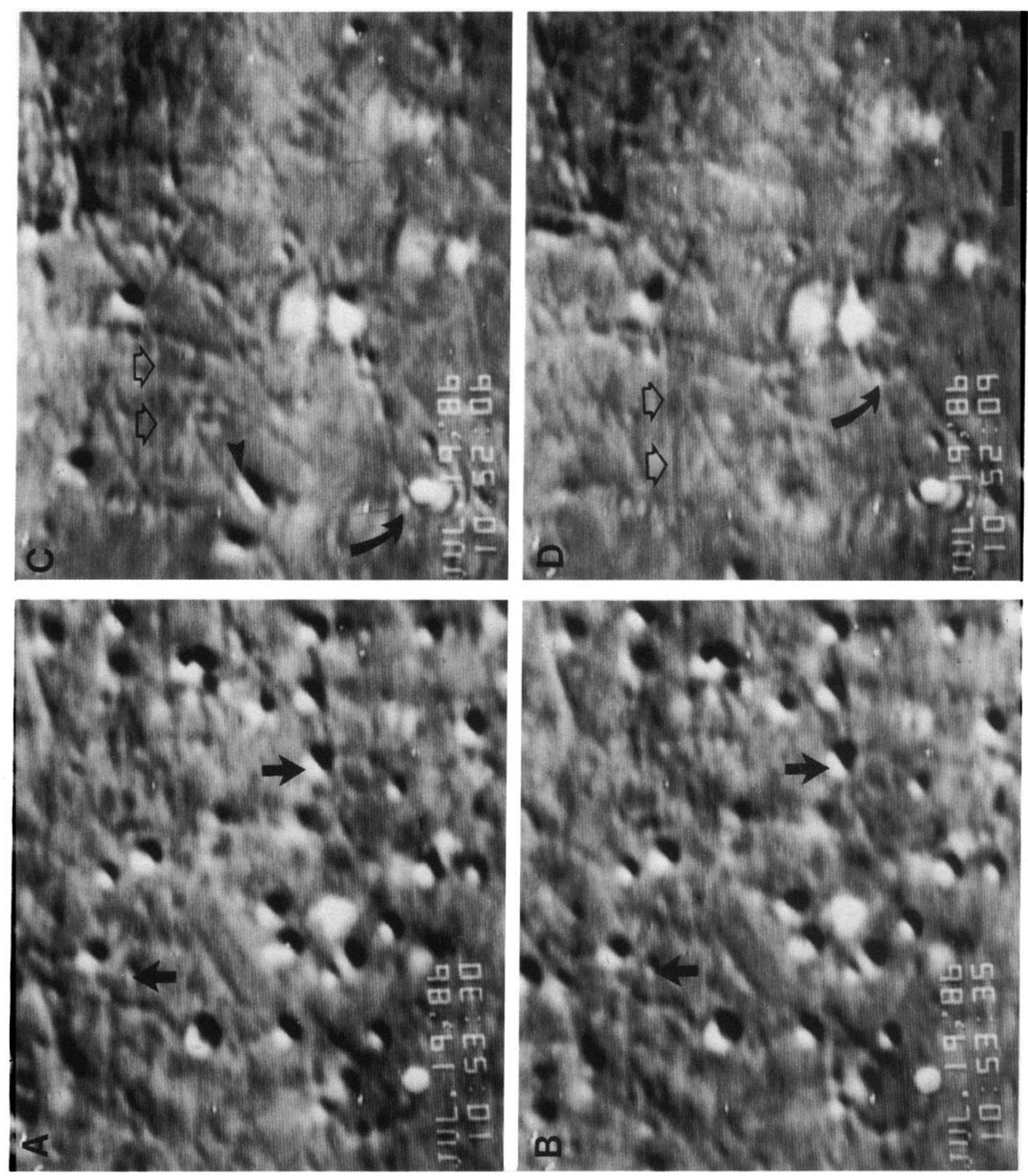
tein kinase partially reduced the inhibitory effect on vesicle movement. These results are analogous to the inhibition of neurotransmitter release by dephospho-synapsin I and the reduction of that inhibition by phosphorylation of synapsin I. Thus, the results are consistent with the possibility that the mechanism by which synapsin I affects organclle movement in the isolated axoplasm is similar or identical to the mechanism by which it regulates synaptic vesicle availability in the presynaptic terminal.

The small vesicles in the axoplasm were clearly not the only organelles affected by synapsin I. Movement of all organelles was dramatically inhibited. This nonselective effect raises the possibility that synapsin I directly inhibits the microtubulebased motor mechanism for fast axonal transport. Several factors, however, suggest that synapsin I does not directly affect the transport mechanism itself. First, synapsin I had no apparent effect on the movement of organelles along microtubules in the periphery of the axoplasm or along isolated microtubules protruding into the buffer, where the concentration of synapsin I was the highest. Furthermore, the ability of synapsin I to inhibit organelle movement was critically dependent on a closely packed cytoskeletal matrix. For example, when the axoplasm was improperly extruded so that the original linear organization of the cytoskeletal network was disturbed, synapsin I was much less effective in inhibiting movement. Also, if a single axoplasm had highly organized regions adjacent to regions where the microtubules were disorganized and extending haphazardly in all directions, then significant inhibition was seen only in the organized regions. This ability of synapsin I to inhibit movement only within the interior of axoplasm in which the original cytoskeletal architecture has been maintained is not consistent with a direct effect on the fast axonal transport mechanism. It is also not consistent with the inhibitory effect depending solely on the concentration of a particular component that may have been diluted below a critical concentration in the buffer surrounding the axoplasm. Rather, it suggests that synapsin I may indirectly inhibit fast axonal transport by crosslinking neighboring axoplasmic structures, thus restricting the ability of organelles to move within the resulting network. However, the absence of an effect of dephospho-synapsin I on organelles moving along individual microtubules or in the periphery of the axoplasm suggests that the organelles are not crosslinked to the microtubules. Instead, some other axoplasmic structure must be required.

One possible mechanism for the inhibition of movement of membranous organelles reported here is the following. Dephospho-synapsin I inhibits synaptic vesicle mobility by crosslinking the vesicles to some component(s) of the cytoskeleton, thereby creating a dense meshwork or cage, which then indirectly restricts the movement of other organelles as well. Indeed, it has previously been proposed that synapsin I crosslinks synaptic vesicles to cytoskeletal structures and that this interaction is regulated by phosphorylation of the synapsin I molecule (De Camilli et al., 1983b; Huttner et al., 1983; Navone et al., 1984). In support of this proposal, synapsin I has been shown to bind with high affinity to isolated synaptic vesicles (Huttner et al., 1983; Schiebler et al., 1986; Steiner et al., 1987; Benfenati et al., 1989) and to interact in vitro with various cytoskeletal structures, including spectrin (Baines and Bennett, 1985; Kanda et al., 1986; Krebs et al., 1987), microtubules (Baines and Bennett, 1986; Goldenring et al., 1986), neurofilaments (Goldenring et al., 1986; Steiner et al., 1987), and F-actin (Bahler and Greengard, 1987; Petrucci and Morrow, 1987; Petrucci et al., 1988; Bahler et al., 1989).

Only in the synaptic vesicle (Huttner et al., 1983; Schiebler et al., 1986; Benfenati et al., 1989) and actin (Bahler and Greengard, 1987; Petrucci and Morrow, 1987; Bahler et al., 1989) studies was the effect of phosphorylation of synapsin I by cAMPdependent protein kinase examined. Phosphorylation by cAMPdependent protein kinase had only a slight effect on the interaction of synapsin I with purified vesicles (Schiebler et al., 1986) and with actin (Bahler and Greengard, 1987). It is not known whether these relatively minor effects are of physiological significance. Phosphorylation of synapsin I by CaM kinase II has been shown to decrease its interaction with purified synaptic vesicles (Huttner et al., 1983; Schiebler et al., 1986; Benfenati et al., 1989) and neurofilaments (Steiner et al., 1987) and to nearly abolish its ability to bundle F-actin (Bahler and Greengard, 1987; Petrucci and Morrow, 1987). Thus, phosphorylation-dependent interactions of synapsin I with any of these componcnts could be responsible for the present findings on organelle movement.

Interaction with neurofilaments is unlikely to explain the effects of synapsin I in both the axoplasm and the presynaptic terminal, since neurofilaments are thought not to extend into the synaptic vesicle-containing region of the terminal (Roots, 1983; Walker et al., 1985). Interaction with microtubules is also unlikely to be the sole explanation for the effects of synapsin I, since no microtubule bundling was observed in the present experiments and phosphorylation of synapsin I, if anything, may enhance the interaction of synapsin I with microtubule proteins (Petrucci and Morrow, 1987). In addition, microtubules are thought not to extend into the synaptic vesicle region of the presynaptic nerve terminal (Roots, 1983; Walker et al., 1985), although evidence for some microtubules extending into the presynaptic terminal does exist (Hirokawa et al., 1989). Regardless, the absence of inhibition by dephospho-synapsin I when organelles are moving along individual microtubules in the absence of other structures (Fig. 4) makes it unlikely that interaction with microtubules is involved.

Interaction with F-actin, on the other hand, could explain both effects. The ability of synapsin I to bundle F-actin in in vitro systems (Bahler and Greengard, 1987; Petrucci and Morrow, 1987; Petrucci et al., 1988) is consistent with synapsin I

Figure 3. Comparison of the effect of dephospho-synapsin I on organelle movement within the interior and near the periphery of the axoplasm. Stills from video records showing organelle movement within the interior $(A, B)$ and near the periphery $(C, D)$ of extruded axoplasm $20-22$ min after addition of $1.3 \mu \mathrm{M}$ dephospho-synapsin I. Arrows in $A$ and $B$ indicate 2 of the numerous organelles in the field that did not move during the $5 \mathrm{sec}$ interval between frames $A$ and $B$. Open arrows in $C$ and $D$ indicate a single microtubule. Solid arrows in $C$ and $D$ indicate the positions of a single organelle that moved along another microtubule during the $3 \mathrm{sec}$ interval between frames $C$ and $D$. In such peripheral regions, movement was generally active to the extent that few organelles remained in the field for more than 2 or 3 sec. Arrowhead in $C$ indicates an organelle that is not seen in $D$ because it had moved out of the field. Stills were made by accumulating 4 frames ( 0.13 sec) from the original videotape using the C-1966 Image Processor and photographing the accumulated image from the monitor onto Kodak TMAX 100 film. Scale bar, $2 \mu \mathrm{m}$. 

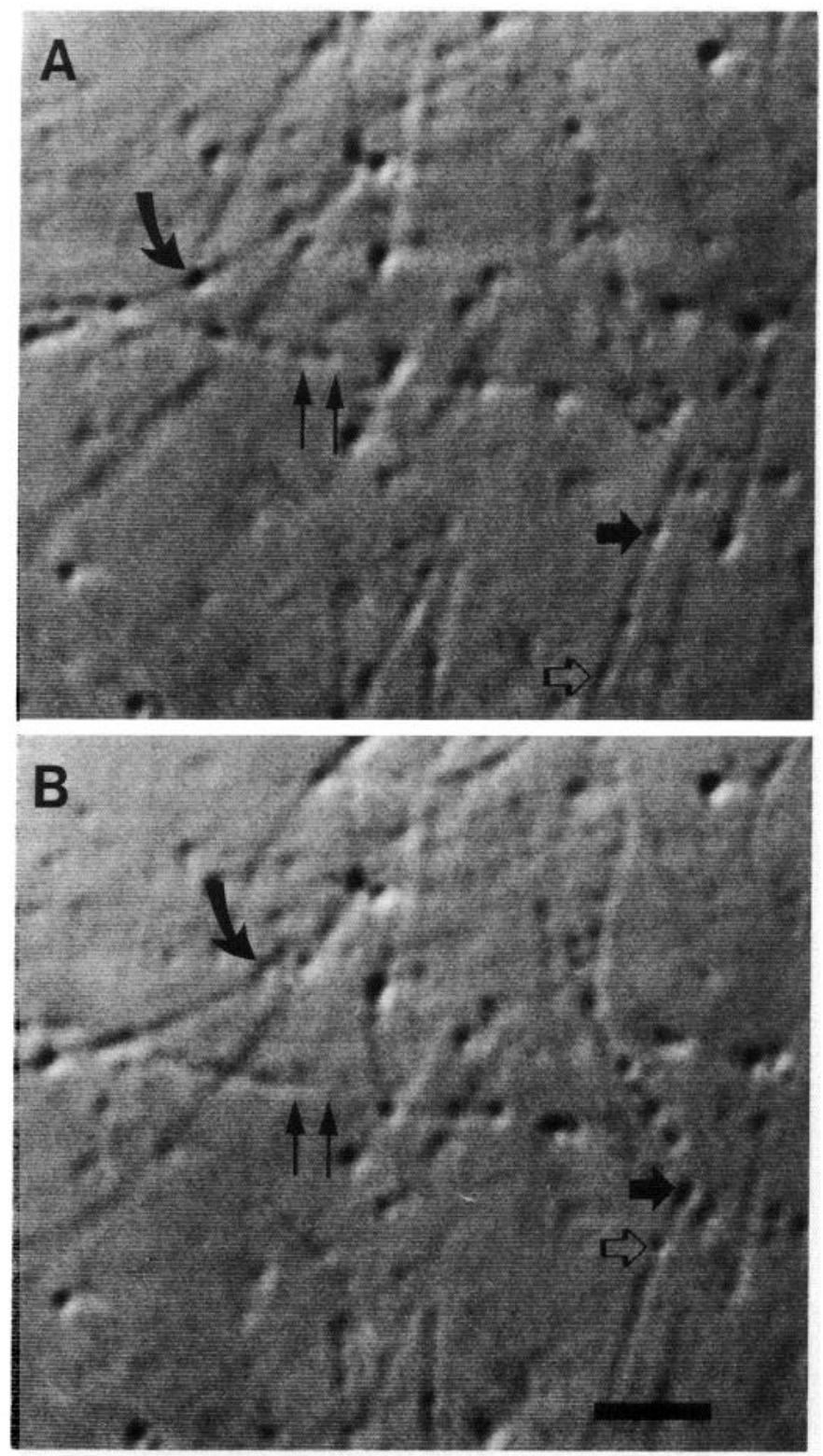

Figure 4. Effect of dephospho-synapsin I on organelle movement along isolated microtubules protruding from the axoplasm into the buffer. Stills from video records show that organelles continue to move along these isolated microtubules $1 \mathrm{hr}$ after addition of $10 \mu \mathrm{M}$ dephosphosynapsin I. Arrows in $A$ point to organelles that moved during the 5.3 sec interval between frames $A$ and $B$. Solid, curved arrows in $A$ and $B$ point to an organelle that moved upward to the left. Thin double arrows in $A$ point to two smaller organelles that are not seen in $B$ because they had moved out of the field. Thin double arrows in $B$ point to the positions originally occupied by these organelles. Short, solid and short, open arrows in the lower right corners of $A$ and $B$ point to two organelles that moved upward along the indicated microtubule. Stills were made as described in the legend to Figure 1. The axoplasm used for this figure is the same axoplasm used for Figure 1. Scale bar, $2 \mu \mathrm{m}$.

affecting organelle mobility via a crosslinking mechanism involving actin microfilaments. The question as to whether actincontaining filaments are distributed predominantly under the axolemma (Chang and Goldman, 1973; Isenberg and Small, 1978; Metuzals and Tasaki, 1978; Hirokawa, 1982; Schnapp and Reese, 1982; Letourneau, 1983) or are also present in significant amounts in the central microtubule-containing regions
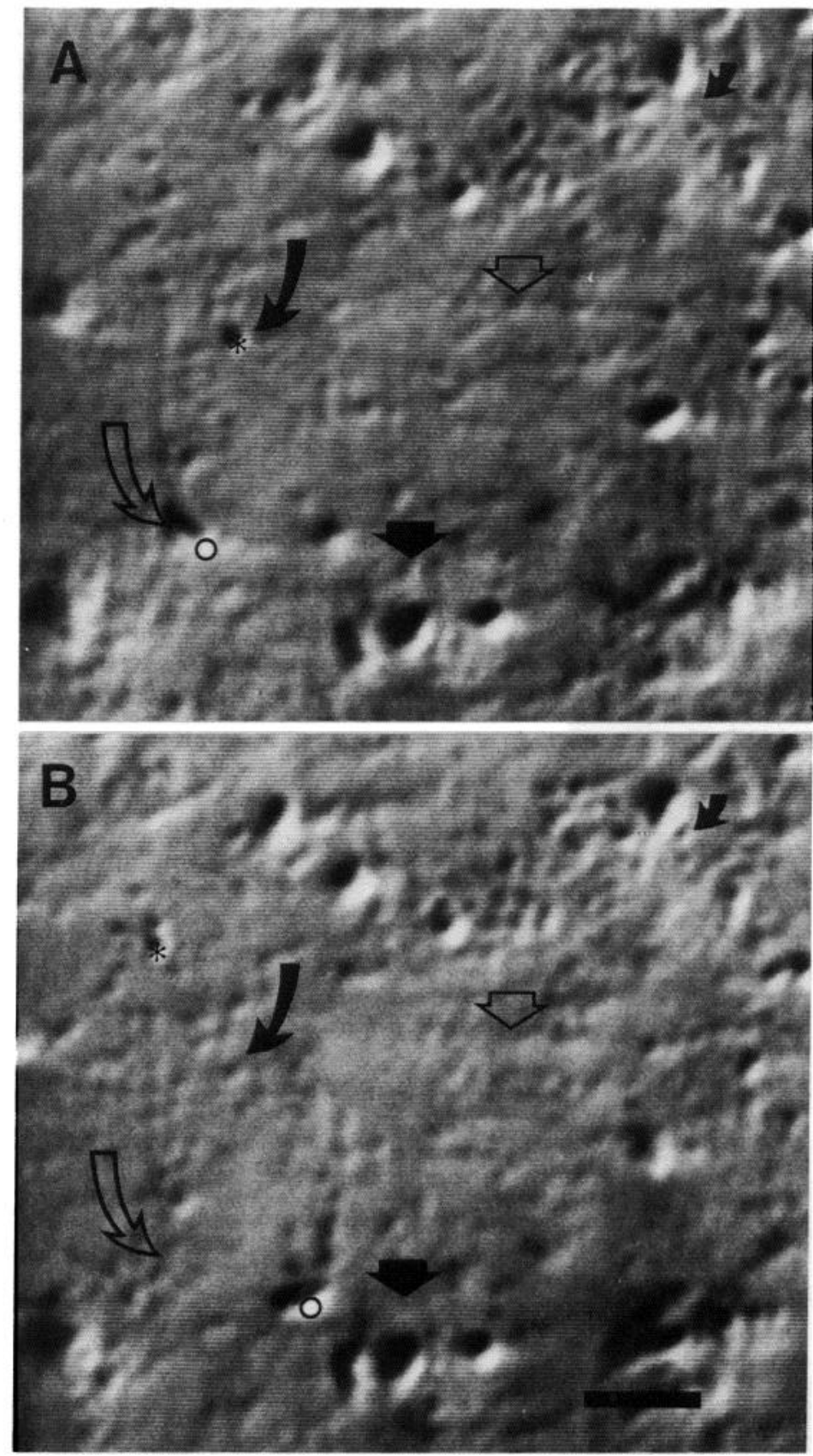

Figure 5. Effect of phosphorylation of synapsin I by CaM kinase II on organelle movement within the interior of the axoplasm. Stills from video records show organelle movement within the interior of isolated axoplasm $1 \mathrm{hr}$ after addition of $10 \mu \mathrm{M}$ tail phospho-synapsin I. Straight arrows and large, curved arrows in $A$ point to a few of the many organelles that moved during the $5.5 \mathrm{sec}$ interval between frames $A$ and $B$. The corresponding symbols in $B$ point to the positions originally occupied by the respective organelles. Solid, curved arrow in $A$ pints to an organelle $\left({ }^{*}\right)$ that moved upward to the left, as seen in B. Open, curved arrow in $A$ points to an organelle (o) that moved to the right in $B$. Solid, straight, and open straight arrows in $A$ point to organelles that had moved out of the field in $B$. The short, curved arrow in the upper right corner of $B$ points to an organelle that was not present in $A$. Stills were made as described in the legend to Figure 1. Scale bar, $2 \mu \mathrm{m}$.

of the axon or neurite (Yamada et al., 1971; LeBeux and Willemot, 1975; Jockusch et al., 1979; Kuczmarski and Rosenbaum, 1979; Spooner and Holladay, 1981; Papasozomenos and Payne, 1986; Fath and Lasek, 1988) has been the subject of 
some dispute. However, actin is clearly present in high concentration in the extruded squid axoplasm (Morris and Lasek, 1984; Fath and Lasek, 1988) and is also found in the presynaptic nerve terminal (LeBeux and Willemot, 1975; Toh et al., 1976; Walker et al., 1985). Moreover, although actin is not necessary for fast axonal transport (Allen et al., 1985; Brady et al., 1985; Schnapp et al., 1985), several actin-binding and microfilament depolymerizing agents have been shown to disrupt fast axonal transport (Goldberg et al., 1980; Goldberg, 1982; Brady et al., 1984). Significantly, these microfilament depolymerizing agents are not effective at inhibiting organelle movement along individual microtubules (Brady, 1987), and the individual microtubules on the periphery do not contain detectable microfilaments (Schnapp et al., 1985; Brady, 1987). Further studies will be required to determine if synapsin I inhibits organelle movement within the squid axoplasm by crosslinking synaptic vesicles with F-actin, by crosslinking F-actin with $\mathrm{F}$-actin, or by some mechanism involving other cytoplasmic component(s) and to determine if such interactions have physiological relevance to synaptic transmission.

Associations between synapsin I and various subcellular components that were produced under the in vitro conditions used in the present study may not occur in vivo. However, it should be noted that the axoplasm studies more nearly resemble physiologically relevant conditions than do studies that examine interactions between synapsin I and purified subcellular components. A variety. of other proteins, including myosin fragments, calcium-free gelsolin, antitubulin antibodies, antimyosin antibodies, and calmodulin (Brady et al., 1985; Johnston et al., 1987; S. T. Brady, unpublished observations; and this report), had little or no effect on transport, indicating that the perturbation of axonal transport by synapsin I was highly specific. In support of the specificity of the action of synapsin I on transport, addition of only 2 phosphate groups to the tail region of the synapsin I molecule virtually abolish its inhibitory effect. Furthermore, it is unlikely that the inhibitory effect of dephosphosynapsin I is an artifact due to the overall surfactant (M. Ho et al., unpublished observations) or basic properties of the molecule, since phosphorylation of synapsin I has no detectable effect on its surface activity (M. Ho et al., unpublished observations) and has only a minimal effect on its isoelectric point. In addition, perfusion of axoplasm with the basic protein avidin had no detectable effect on movement of organelles (unpublished observations).

Synapsin I constitutes $\sim 0.4 \%$ of mammalian cerebral cortex protein (corresponding to approximately $1.0 \%$ of total neuronal protein) (Goelz et al., 1981) and most of the synapsin I appears to be localized to presynaptic terminals (De Camilli et al., 1983a, b; Huttner et al., 1983). Indeed, synapsin I represents $6 \%$ of the total protein present in synaptic vesicle fractions isolated from nerve terminal endings (Huttner et al., 1983). Squid axoplasm contains approximately $25 \mathrm{mg} / \mathrm{ml}$ protein (Morris and Lasek, 1984); thus, the effective concentrations of synapsin I used in the present experiments, namely $1.3-10 \mu \mathrm{M}$, correspond to about $0.4-3.0 \%$ of total protein in the extruded axoplasm. These concentrations are probably higher than that which exists in axons, since synapsin I constitutes only $0.02 \%$ of total protein in the corpus callosum (Goelz et al., 1981). In addition, it appears that only a portion of the synapsin I present in the axon is associated with vesicles during their transport down the axon, with the remainder undergoing slow axonal transport independent of membranous organelles (Baitinger and Willard, 1987). Thus, the concentrations of synapsin I used in the present experiments are most likely reached only in synaptic terminals where synapsin I is specifically localized. Therefore, we do not propose that synapsin I regulates release by blocking fast axonal transport. In fact (Llinas et al., unpublished observations), disruption of microtubules or axonal transport could not account for the inhibition of neurotransmitter release by synapsin I. Instead, we suggest that the ability of synapsin I to block axonal transport might reflect its ability to modulate organelle movement in the nerve terminal. Such modulation might involve regulating release of the vesicles from the microtubules, targeting the released vesicles to a cytoskeletal (actin?) matrix, or regulating detachment of the vesicles from such a cyloskeletal matrix.

\section{References}

Adams, R. J., and D. Bray (1983) Rapid transport of foreign particles microinjected into crab axons. Nature (London) 303: 718-720.

Allen, R. D., and N. S. Allen (1983) Video-enhanced microscopy with a computer frame memory. J. Microsc. 129: 3-17.

Allen, R. D., N. S. Allen, and J. L. Travis (1981) Video-enhanced contrast, differential interference contrast (AVEC-DIC) microscopy A new method capable of analyzing microtubule-related motility in the reticulopodial network of Allogromia laticollaris. Cell Motil. 1: 291-302.

Allen, R. D., J. Metuzals, I. Tasaki, S. T. Brady, and S. P. Gilbert (1982) Fast axonal transport in squid giant axon. Science 218: 11271129.

Allen, R. D., D. G. Weiss, J. H. Hayden, D. T. Brown, H. Fujiwake, and $M$. Simpson (1985) Gliding movement of and bidirectional transport along single native microtubules from squid axoplasm: Evidence for an active role of microtubules in cytoplasmic transport. $\mathrm{J}$ Cell Biol. 100: 1736-1752.

Bahler, M., and P. Greengard (1987) Synapsin I bundles F-actin in a phosphorylation-dependent manner. Nature (London) 326: 704-707.

Bahler, M., Benfenati, F., Valtorta, F., Czernik, A. J. and P. Greengard (1989) Characterization of synapsin I fragments produced by cystcine-specific cleavage: A study of their interactions with F-actin. J. Cell Biol. 108: 1841-1849.

Baines, A. J., and V. Bennett (1985) Synapsin I is a spectrin-binding protein immunologically related to erythrocyte protein 4.1 . Nature (London) 315: 410-413.

Baines, A. J., and V. Bennett (1986) Synapsin I is a microtubulebundling protein. Nature (London) 319: 145-147.

Baitinger, C., and M. Willard (1987) Axonal transport of synapsin I-like proteins in rabbit retinal ganglion cells. J. Neurosci. 7: 37233735.

Benfenati, F., M. Bähler, R. Jahn, and P. Greengard (1989) Interactions of synapsin I with small synaptic vesicles: Distinct sites in synapsin I bind to vesicle phospholipids and vesicle proteins. J. Cell Biol. 108: $1863-1872$.

Brady, S. T. (1987) Fast axonal transport in isolated axoplasm from squid giant axon. In Axonal Transport, R. S. Smith and M. Bisby, eds., pp. 113-138, Liss, New York.

Brady, S. T., R. J. Lasek, and R. D. Allen (1982) Fast axonal transport in extruded axoplasm from squid giant axon. Science 218: 1129 1131.

Brady, S. T., R. J. Lasek, R. D. Allen, H. L. Yin, and T. P. Stossel (1984) Gelsolin inhibition of fast axonal transport indicates a requirement for actin microfilaments. Nature (London) 310: 56-58.

Brady, S. T., R. J. Lasek, and R. D. Allen (1985) Video microscopy of fast axonal transport in extruded axoplasm: A new model for study of molecular mechanisms. Cell Motil. 5: 81-101.

Chang, C.-M., and R. D. Goldman (1973) The localization of actinlike fibers in cultured neuroblastoma cells as revealed by heavy meromyosin binding. J. Cell Biol. 57: 867-874.

Czernik, A. J., D. T. Pang, and P. Greengard (1987) Amino acid sequences surrounding the cAMP-dependent and calcium/calmodulin-dependent phosphorylation sites in rat and bovine synapsin I. Proc. Natl. Acad. Sci. USA 84: 7518-7522.

De Camilli, P., and P. Greengard (1986) Synapsin I: A synaptic vesicleassociated neuronal phosphoprotein. Biochem. Pharmacol. 35: 43494357 . 
De Camilli, P., T. Ueda, F. E. Bloom, and P. Greengard (1979) Widespread distribution of protein $I$ in the central and peripheral nervous systems. Proc. Natl. Acad. Sci. USA 76: 5977-5981.

De Camilli, P., R. Cameron, and P. Greengard (1983a) Synapsin I (protein I), a nerve terminal-specific phosphoprotein. I. Its general distribution in synapses of the central and peripheral nervous system demonstrated by immunofluorescence in frozen and plastic sections. J. Cell Biol. 96: 1337-1354.

De Camilli, P., S. M. Harris, Jr., W. B. Huttner, and P. Greengard (1983b) Synapsin I (protein I), a nerve terminal-specific phosphoprotein. II. Its specific association with synaptic vesicles demonstrated by immunocytochemistry in agarose-embedded synaptosomes. J. Cell Biol. 96: 1355-1373.

Fath, K., and R. J. Lasek (1988) Two classes of actin microfilaments are associated with the inner cytoskeleton of axons. J. Cell Biol. 107: 613-621.

Forman, D. S., K. J. Brown, and D. R. Livengood (1983) Fast axonal transport in permeabilized lobster giant axons is inhibited by vanadate. J. Neurosci. 3: 1279-1288.

Forscher, P., L. K. Kaczmarek, J. Buchanan, and S. J. Smith (1987) Cyclic AMP induces changes in distribution and transport of organelles within growth cones of Aplysia bag cell neurons. J. Neurosci. 7: 3600-3611.

Goelz, S. E., E. J. Nestler, B. Chehrazi, and P. Greengard (1981) Distribution of protein I in mammalian brain as determined by a detergent-based radioimmunoassay. Proc. Natl. Acad. Sci. USA 78: 2130 2134.

Goldberg, D. J. (1982) Microinjection into an identified axon to study the mechanism of fast axonal transport. Proc. Natl. Acad. Sci. USA 74: $4818-4822$.

Goldberg, D. J., D. A. Harris, B. W. Lubit, and J. H. Schwartz (1980) Analysis of the mechanism of fast axonal transport by intracellular injection of potentially inhibitory macromolecules: Evidence for a possible role of actin filaments. Proc. Natl. Acad. Sci. USA 77: 74487452.

Goldenring, J. R., R. S. Lasher, M. L. Vallano, T. Ueda, S. Naito, N. H. Sternberger, L. A. Sternberger, and R. J. DeLorenzo (1986) Association of synapsin I with neuronal cytoskeleton. J. Biol. Chem. 261: 8495-8504.

Grafstein, B., and D. S. Forman (1980) Intracellular transport in neurons. Physiol. Rev. 60: 1167-1283.

Grand, R. J. A., S. V. Perry, and R. A. Weeks (1979) Troponin C-like proteins (calmodulins) from mammalian smooth muscle and other tissues. Biochem. J. 177: 521-529.

Greengard, P., M. D. Browning, T. L. McGuinness, and R. Llinas (1987) Synapsin I, a phosphoprotein associated with synaptic vesicles: Possible role in regulation of neurotransmitter release. In Molecular Mechanisms of Neuronal Responsiveness, Y. H. Ehrlich, R. H. Lenox, E. Kornecki, and W. O. Berry, eds., pp. 135-153, Plenum, New York.

Hayden, J. H., R. D. Allen, and R. D. Goldman (1983) Cytoplasmic transport in keratocytes: Direct visualization of particle translocation along microtubules. Cell Motil. 3: 1-19.

Hirokawa, N. (1982) Cross-linker system between neurofilaments, microtubules and membranous organelles in frog axons revealed by the quick-freeze, deep-etching method. J. Cell Biol. 94: 129-142.

Hirokawa, N., K. Sobue, K. Kanda, A. Harada, and H. Yorifuji (1989) The cytoskeletal architecture of the presynaptic terminal and molecular structure of synapsin I. J. Cell Biol. 108: 111-126.

Hollenbeck, P. J., and D. Bray (1987) Rapidly transported organelles containing membrane and cytoskeletal components: Their relation to axonal growth. J. Cell Biol. 105: 2827-2835.

Huttner, W. B., and P. Greengard (1979) Multiple phosphorylation sites in protein I and their differential regulation by cyclic AMP and calcium. Proc. Natl. Acad. Sci. USA 76: 5402-5406.

Huttner, W. B., L. J. DeGennaro, and P. Greengard (1981) Differential phosphorylation of multiple sites in purified protein I by cyclic AMPdependent and calcium-dependent protein kinases. J. Biol. Chem. 256: 1482-1488.

Huttner, W. B., W. Schiebler, P. Greengard, and P. De Camilli (1983) Synapsin I (protein I), a nerve terminal-specific phosphoprotein. III. Its association with synaptic vesicles studied in a highly purified synaptic vesicle preparation. J. Cell Biol. 96: 1374-1388.

Inoue, S. (1981) Video image processing greatly enhances contrast, quality, and speed in polarization-based microscopy. J. Cell Biol. 89: 346-356.
Isenberg, G., and J. V.Small (1978) Filamentous actin, $100 \AA$ filaments and microtubules in neuroblastoma cells. Their distribution in relation to sites of movement and neuronal transport. Eur. J. Cell Biol. 16: 326-344.

Jockusch, H., B. M. Jockusch, and M. M. Burger (1979) Nerve fibers in culture and their interaction with non-neural cells visualized by immunofluorescence. J. Cell Biol. 80: 629-641.

Johnston, K. M., S. T. Brady, D. van der Kooy, and J. A. Connolly (1987) A unique tubulin antibody which disrupts particle movement in squid axoplasm. Cell Motil. Cytoskel. 7: 110-115.

Kaczmarek, L. K., K. R. Jennings, F. Strumwasser, A. C. Nairn, U. Walter, F. D. Wilson, and P. Greengard. (1980) Microinjection of catalytic subunit of cyclic AMP-dependent protein kinase enhances calcium action potentials of bag cell neurons in cell culture. Proc. Natl. Acad. Sci. USA 77: 7487-7491.

Kanda, K., T. Tanaka, and K. Sobue (1986) Calspectin (fodrin or nonerythroid spectrin)-actin interaction: A possible involvement of 4.1-related protein. Biochim. Biophys. Res. Commun. 140: 10511058 .

Kennedy, M. B., and P. Greengard (1981) Two calcium/calmodulindependent protein kinases, which are highly concentrated in brain, phosphorylate protein I at distinct sites. Proc. Natl. Acad. Sci. USA 78: 1293-1297.

Kennedy, M. B., T. McGuinness, and P. Greengard (1983) A calcium/ calmodulin-dependent protein kinase from mammalian brain that phosphorylates synapsin I: Partial purification and characterization. J. Neurosci. 3: 818-831.

Koenig, E. (1986) Isolation of native Mauthner cell axoplasm and an analysis of organelle movement in non-aqueous and aqueous media. Brain Res. 398: 288-297.

Krebs, K. E., I. S. Zagon, and S. R. Goodman (1987) Amelin: A 4.1related spectrin-binding protein found in neuronal cell bodies and dendrites. J. Neurosci. 7: 3907-3914.

Kuczmarski, E. R., and J. L. Rosenbaum (1979) Studies on the organization and localization of actin and myosin in neurons. J. Cell Biol. 80: 356-371.

LeBeux, Y. J., and J. Willemot (1975) An ultrastructural study of the microfilaments in rat brain by means of E-PTA staining and heavy meromyosin labeling. II. The synapses. Cell Tissue Res. 160: 37-68.

Letourneau, P. C. (1983) Differences in the organization of actin in the growth cones compared with the neurites of culture neurons from chick embryos. J. Cell Biol. 97: 963-973.

Llinas, R., I. Z. Steinberg, and K. Walton (1981) Relationship between presynaptic calcium current and postsynaptic potential in squid giant synapse. Biophys. J. 33: 323-352.

Llinas, R., T. L. McGuinness, C. S. Leonard, M. Sugimori, and P. Greengard (1985) Intraterminal injection of synapsin I or calcium/ calmodulin-dependent protein kinase II alters neurotransmitter release at the squid giant synapse. Proc. Natl. Acad. Sci. USA 82: 30353039.

McGuinness, T. L., Y. Lai, and P. Greengard (1985) $\mathrm{Ca}^{2+} /$ calmodulindependent protein kinase II: Isozymic forms from rat forebrain and cerebellum. J. Biol. Chem. 260: 1696-1704.

McGuinness, T. L., S. T. Brady, J. A. Gruner, M. Sugimori, R. Llinas, and P. Greengard (1987) Inhibition by synapsin I of membranous organelle movement in isolated squid axoplasm. Soc. Neurosci. Abstr. 13: 1239.

Metuzals,.J., and I. Tasaki (1978) Subaxolemmal filamentous network in the giant nerve fiber of the squid (Loligo pealei L.) and its possible role in excitability. J. Cell Biol. 78: 597-621.

Miller, R. H., and R. J. Lasek (1985) Cross-bridges mediate anterograde and retrograde vesicle transport along microtubules in squid axoplasm. J. Cell Biol. 101: 2181-2193.

Morris, J. R., and R. J. Lasek (1984) Monomer-polymer equilibria in the axon: Direct measurement of tubulin and actin as polymer and monomer in axoplasm. J. Cell Biol. 98: 2064-2076.

Nairn, A. C., and P. Greengard (1987) Purification and characterization of $\mathrm{Ca}^{2+} / \mathrm{calmodulin}$-dependent protein kinase I from bovine brain J. Biol. Chem. 262: 7273-7281.

Navone, F., P. Greengard, and P. De Camilli (1984) Synapsin I in nerve terminals: Selective association with small synaptic vesicles. Science 226: 1209-1211.

Nestler, E. J., and P. Greengard (1984) Protein Phosphorylation in the Nervous System, pp. 144-153, Wiley, New York. 
Papasozomenos, S. C., and M. R. Payne (1986) Actin immunoreactivity localizes with segregated microtubules and membranous organelles and in the subaxolemmal region in the $\beta, \beta^{\prime}$-iminodipropionitrile axon. J. Neurosci. 6: 3483-3491.

Paschal, B. M., and R. B. Vallee (1987) Retrograde transport by the microtubule-associated protein MAP 1C. Nature (London) 330:181183.

Paschal, B. M., H. S. Shpetner, and R. B. Vallee (1987) MAP-1C is a microtubule-activated ATPase which translocates microtubules in vitro and has dynein-like properties. J. Cell Biol. 105: 1273-1282.

Peterson, G. L. (1977) A simplification of the protein assay method of Lowry et al. which is more generally applicable. Anal. Biochem. 83: 346-356.

Petrucci, T. C., and J. S. Morrow (1987) Synapsin I: An actin-bundling protein under phosphorylation control. J. Cell Biol. 105: 1355-1363.

Petrucci, T. C., M. S. Mooseker, and J. S. Morrow (1988) A domain of synapsin I involved with actin bundling shares immunologic crossreactivity with villin. J. Cell Biochem. 36: 25-35.

Roots, B. I. (1983) Neurofilament accumulation induced in synapses by leupeptin. Science 221: 971-972.

Schiebler, W., R. Jahn, J.-P. Doucet, J. Rothlein, and P. Greengard (1986) Characterization of synapsin I binding to small synaptic vesicles. J. Biol. Chem. 261: 8383-8390.

Schnapp, B. J., and T. S. Reese (1982) Cytoplasmic structure in rapidfrozen axons. J. Cell Biol. 94: 667-679.

Schnapp, B. J., R. D. Vale, M. P. Sheetz, and T. S. Reese (1985) Single microtubules from squid axoplasm support bidirectional movement of organelles. Cell 40: 455-462.

Schroer, T. A., S. T. Brady, and R. B. Kelly (1985) Fast axonal transport of foreign synaptic vesicles in squid axoplasm. J. Cell Biol. 101: 568-572.

Sieghart, W., J. Forn, and P. Greengard (1979) $\mathrm{Ca}^{2+}$ and cyclic AMP regulate phosphorylation of the same two membrane-associated proteins specific to nerve tissue. Proc. Natl. Acad. Sci. USA 76: 24752479.

Spooner, B. S., and C. R. Holladay (1981) Distribution of tubulin and actin in neurites and growth cones of differentiating nerve cells. Cell Motil. 1: 167-178.
Steiner, J. P., E. Ling, and V. Bennett (1987) Nearest neighbor analysis for brain synapsin I. J. Biol. Chem. 262: 905-914.

Titus, J. A., R. Haugland, S. O. Sharrow, and D. M. Segal (1982) Texas red, a hydrophilic, red-emitting fluorophore for use with fluorescein in dual paramater flow microfluorometric and fluorescence microscopic studies. J. Immunol. Methods 50: 193-204.

Toh, B. H., H. A. Gallichio, P. L. Jeffrey, B. G. Livett, H. K. Muller, M. N. Cauchi, and F. M. Clarke (1976) Anti-actin stains synapses. Nature (London) 264: 648-650.

Ueda, T., and P. Greengard (1977) Adenosine 3',5'-monophosphateregulated phosphoprotein system of neuronal membranes. I. Solubilization, purification, and some properties of an endogenous phosphoprotein. J. Biol. Chem. 252: 5155-5163.

Ueda, T., H. Maeno, and P. Greengard (1973) Regulation of endogenous phosphorylation of specific proteins in synaptic membrane fractions from rat brain by adenosine $3^{\prime}, 5^{\prime}$-monophosphate. J. Biol. Chem. 248: 8295-8305.

Vale, R. D., B. J. Schnapp, T. Mitchison, E. Steuer, T. S. Reese, and M. P. Scheetz (1985a) Different axoplasmic proteins generate movement in opposite directions in vitro. Cell 43: 623-632.

Vale, R. D., B. J. Schnapp, T. S. Reese, and M. P. Scheetz (1985b) Movement of organelles along filaments dissociated from the axoplasm of the squid giant axon. Cell 40: 449-454.

Vale, R. D., B. J. Schnapp, T. S. Reese, and M. P. Scheetz (1985c) Identification of a novel force-generating protein, kinesin, involved in microtubule-based motility. Cell 42: 39-50.

Walker, J. H., C. M. Boustead, V. Witzemann, G. Shaw, K. Weber, and M. Osborn (1985) Cytoskeletal proteins at the cholinergic synapse: Distribution of desmin, actin, fodrin, neurofilaments, and tubulin in Torpedo electric organ. Eur. J. Cell Biol. 38: 123-133.

Weiss, D. G. (1986) Visualization of the living cytoskeleton by videoenhanced microscopy and digital image processing. J. Cell Sci. [Suppl.] 5: $1-15$.

Yamada, K. M., B. S. Spooner, and N. K. Wessells (1971) Ultrastructure and function of growth cones and axons of cultured nerve cells. J. Cell Biol. 49: 614-635. 